\title{
REST is a major negative regulator of endocrine differentiation during pancreas organogenesis
}

\author{
Meritxell Rovira, ${ }^{1,2,3,4}$ Goutham Atla, ${ }^{5}$ Miguel Angel Maestro, ${ }^{5,6}$ Vane Grau, ${ }^{5,6}$ Javier García-Hurtado, ${ }^{5,6}$ \\ Maria Maqueda, ${ }^{7}$ Jose Luis Mosquera, ${ }^{7}$ Yasuhiro Yamada, ${ }^{8}$ Julie Kerr-Conte, ${ }^{9}$ Francois Pattou, \\ and Jorge Ferrer ${ }^{5,6,10}$ \\ ${ }^{1}$ Department of Physiological Science, School of Medicine, Universitat de Barcelona (UB), L'Hospitalet de Llobregat, Barcelona \\ 08907, Spain; ${ }^{2}$ Pancreas Regeneration: Pancreatic Progenitors and Their Niche Group, Regenerative Medicine Program, Institut \\ d'Investigació Biomèdica de Bellvitge (IDIBELL), L'Hospitalet de Llobregat, Barcelona 08908, Spain; ${ }^{3}$ Program for Advancing the \\ Clinical Translation of Regenerative Medicine of Catalonia (P-CMR[C]), L'Hospitalet de Llobregat, Barcelona 08908, Spain; ${ }^{4}$ Center \\ for Networked Biomedical Research on Bioengineering, Biomaterials, and Nanomedicine (CIBER-BBN), Madrid 28029, Spain; \\ ${ }^{5}$ Regulatory Genomics and Diabetes, Centre for Genomic Regulation, Barcelona Institute of Science and Technology, Barcelona \\ 08003, Spain; ${ }^{6}$ Centro de Investigación Biomédica en Red Diabetes y Enfermedades Metabólicas Asociadas (CIBERDEM), Madrid \\ 28029, Spain; ${ }^{7}$ Bioinformatics Unit, Bellvitge Biomedical Research Institute, IDIBELL, L'Hospitalet del Llobregat, Barcelona 08908, \\ Spain; ${ }^{8}$ Division of Stem Cell Pathology, Center for Experimental Medicine and Systems Biology, Institute of Medical Science, \\ University of Tokyo, Tokyo 108-8639, Japan; ${ }^{9}$ Institute Pasteur Lille, University of Lille, Institut National de la Santé et de la \\ Recherche Médicale (INSERM), Centre Hospitalier Universitaire de Lille (CHU Lille), U1190, European Genomic Institute for \\ Diabetes (EGID), Lille F-59000, France; ${ }^{10}$ Department of Metabolism, Digestion, and Reproduction, Section of Genetics and \\ Genomics, Imperial College London, London W12 0NN, United Kingdom
}

Multiple transcription factors have been shown to promote pancreatic $\beta$-cell differentiation, yet much less is known about negative regulators. Earlier epigenomic studies suggested that the transcriptional repressor REST could be a suppressor of endocrinogenesis in the embryonic pancreas. However, pancreatic Rest knockout mice failed to show abnormal numbers of endocrine cells, suggesting that REST is not a major regulator of endocrine differentiation. Using a different conditional allele that enables profound REST inactivation, we observed a marked increase in pancreatic endocrine cell formation. REST inhibition also promoted endocrinogenesis in zebrafish and mouse early postnatal ducts and induced $\beta$-cell-specific genes in human adult duct-derived organoids. We also defined genomic sites that are bound and repressed by REST in the embryonic pancreas. Our findings show that REST-dependent inhibition ensures a balanced production of endocrine cells from embryonic pancreatic progenitors.

[Keywords: REST; $\beta$ cells; bipotent progenitors; endocrine differentiation; pancreas; pancreas development; transcriptional repressors]

Supplemental material is available for this article.

Received March 24, 2021; revised version accepted July 15, 2021.

Progress in our understanding of the transcriptional mechanisms underlying pancreatic $\beta$-cell differentiation has been crucial for recent advances in the development of regenerative therapy strategies for type 1 diabetes mellitus, including efforts to generate functional $\beta$ cells from stem cells, organoids, or in vivo reprograming (Rezania et al. 2014; Huch and Koo 2015; Zhou and Melton 2018). Pancreatic islet cell transcription is also central to the mechanisms that underlie various forms of diabetes (Servitja and Ferrer 2004; Guo et al. 2013; Miguel-Escalada et al. 2019).

Corresponding authors: jorge.ferrer@crg.eu, mrovira@idibell.cat Article published online ahead of print. Article and publication date are online at http://www.genesdev.org/cgi/doi/10.1101/gad.348501.121. Freely available online through the Genes \& Development Open Access option.
Cellular programming and differentiation result from an interplay of positive and negative transcriptional regulatory mechanisms (Crews and Pearson 2009; Graf and Enver 2009). Several DNA binding transcription factors are known to promote endocrine differentiation during pancreas development (Sussel et al. 1998; Gradwohl et al. 2000; Osipovich et al. 2014; De Vas et al. 2015). A more limited number of transcriptional regulators, such as HES1 and TEAD-YAP, have been shown to exert negative endocrine regulation (Jensen et al. 2000; Cebola et al. 2015; Mamidi et al. 2018). Some lines of evidence have also suggested that the RE-1 silencing transcription factor (REST; also known as NRSF, for neural-restrictive

(C) 2021 Rovira et al. This article, published in Genes \& Development, is available under a Creative Commons License (Attribution 4.0 International), as described at http://creativecommons.org/licenses/by/4.0/. 
silencing factor) could be a negative regulator of endocrine differentiation during pancreas development (van Arensbergen et al. 2010).

REST is best known for its role as a suppressor of neuronal genes in nonneuronal cell types (Schoenherr and Anderson 1995). It binds a 21-bp DNA recognition sequence and has two repressor domains that recruit corepressor complexes. Consistent with its function to inhibit neuronal genes, REST is largely expressed in nonneuronal cell types. However, REST is not expressed in endocrine cell lines, and several genes that are repressed by REST are active in islet cells (Atouf et al. 1997; Martin et al. 2008, 2012). Furthermore, genome-wide studies in embryonic stem cells and nonneuronal cell types have shown direct binding of REST near $\beta$-cell-enriched genes (Johnson et al. 2008; van Arensbergen et al. 2010; Mukherjee et al. 2016). REST binding sites in embryonic stem cells overlap with genomic regions that carry Polycomb-repressed chromatin in FACS-purified multipotent progenitors of the early embryonic pancreas (van Arensbergen et al. 2010). Many of these Polycomb-repressed regions are $\beta$-cell regulatory genes that are subsequently derepressed during pancreatic endocrine differentiation, in parallel with the concomitant loss of REST expression (van Arensbergen et al. 2010). These correlations suggested that REST could be an important negative regulator of the endocrine differentiation program of the developing pancreas. A recent report exploited this notion by inhibiting REST to enhance PDX1-mediated activation of endocrine genes in adult pancreatic exocrine cells (Elhanani et al. 2020).

Genetic loss-of-function studies, however, failed to support a significant role of REST in pancreatic endocrine differentiation. Cre/LoxP-based excision of Rest in pancreatic progenitors led to changes in the expression of some endocrine genes but did not affect the number of endocrine cells, suggesting it was not an essential modulator of endocrine differentiation (Martin et al. 2015). Another pancreas deletion study reported that REST tempers pancreatic tissue damage and prevents acinoductal metaplasia, but the study did not explicitly assess endocrine differentiation (Bray et al. 2020). These studies, however, used an allele that removes Rest exon 2 (Gao et al. 2011). Recent work using a gene trap that disrupts transcription from all Rest promoters revealed dramatic effects on embryonic neurogenesis that were not observed when targeting Rest exon 2 (Nechiporuk et al. 2016). The same study showed that excision of Rest exon 2 does not prevent translation of a Cterminal REST peptide that is able to bind DNA, recruit corepressors, and repress target genes (Nechiporuk et al. 2016). Existing data, therefore, warrant a need to explore the true impact of REST in pancreatic endocrine differentiation using alternative genetic tools.

We have now inactivated Rest in the embryonic pancreas using a conditional allele that led to a marked increase in endocrine differentiation, proliferation, and cell mass. Inactivation of Rest in adult mature duct cells, however, failed to elicit this effect. We used chemical inhibitors to show that REST function is conserved in zebrafish and represses endocrine genes in human pancreas organoids. Finally, we defined key properties of the REST-depen- dent program during pancreas organogenesis. Our results, therefore, show an essential role of REST as a major negative regulator of pancreatic endocrine differentiation.

\section{Results}

\section{REST expression in pancreas is largely restricted to progenitors and duct cells}

The expression of REST in pancreatic cell types has been difficult to resolve unequivocally owing to low expression levels and lack of robust antibodies (van Arensbergen et al. 2010; Martin et al. 2015). We found nuclear REST immunoreactivity in most nonendocrine epithelial and mesenchymal cells of the mouse E12.5 pancreas, whereas from E14.5 onward it was largely restricted to duct-like clusters, and absent from acinar and endocrine cell clusters (Supplemental Fig. S1A). Purified duct cells from adult and E18.5 Sox9-eGFP transgenic mice (Gong et al. 2003) confirmed Rest mRNA expression in duct cells (Supplemental Fig. S1B,C). Finally, single-cell RNA-seq data (Tabula Muris et al. 2018) showed Rest mRNA in adult duct and nonepithelial cells but not in acinar or endocrine cells (Supplemental Fig. S1D). These results reinforce the notion that REST is expressed in embryonic bipotent progenitors and adult pancreatic ductal cells but is not detected in endocrine cells, consistent with a potential function of REST as a negative regulator of pancreatic endocrine differentiation.

\section{REST inactivation in pancreatic progenitors induces Neurog3}

Previous genetic studies concluded that genetic ablation of Rest in pancreatic multipotent progenitors has no impact on the formation of NEUROG3+ endocrine precursors or hormone-producing cells (Martin et al. 2015), although this was examined in a mouse model that creates a deletion of Rest exon 2, which produces a functional isoform that can still bind DNA and recruit corepressors (Nechiporuk et al. 2016). We thus used an allele that enables conditional excision of exon 4, which encodes $>75 \%$ of REST protein residues (Yamada et al. 2010). Breeding this line with a $P d \times 1$-Cre transgene (Gu et al. 2002) enabled the excision of Rest and a severe depletion of REST protein in most embryonic pancreatic epithelial cells (hereafter referred to as Rest ${ }^{\mathrm{pKO}}$ mice) (Supplemental Fig. S2A-C).

Previous work showed that REST binds to pancreatic endocrine regulatory genes in mouse ES cells and that during embryonic pancreas differentiation, REST target genes loose Polycomb-repressed chromatin and undergo transcriptional activation (van Arensbergen et al. 2010). To directly test whether this means that REST truly acts as a repressor of endocrine differentiation during pancreas development, we examined expression of the endocrine lineage-determinant NEUROG3 in Rest $^{\mathrm{pKO}}$ embryos. This showed a 3.0 -fold \pm 0.03 -fold increase of Neurog3 mRNA in pancreas from Rest $^{\mathrm{pKO}}$ versus control E13.5 embryos (SEM, Student's t-test $P<0.01)$ and 1.7 -fold 
increased NEUROG3 protein $(P<0.05)$ (Fig. 1A,B). At E18.5, a time point in which the wave of NEUROG3+ cells have normally begun to wane, Neurog3 mRNA was 10.7 -fold \pm 1.2 -fold higher in Rest $^{\mathrm{pKO}}$ embryos $(P<0.01)$ (Fig. 1A). Furthermore, E18.5 mutant pancreas showed an approximately sixfold increase in NEUROG3+ cells normalized by the total number of $\mathrm{CK} 19^{+}$cells $(P<0.01)$ (Fig. 1C). Several NEUROG3+ cells in mutant pancreas appeared to line the epithelium of large ducts (Fig. 1C). Therefore, REST inactivation in pancreatic progenitors led to an increased yield of NEUROG3+ cells throughout embryogenesis.

During normal pancreas development, the activation of Neurog3 is followed by cell cycle exit of most progenitor cells (Miyatsuka et al. 2011; Krentz et al. 2017). This change in cell cycle activity has been shown to occur in discrete, strongly expressing NEUROG3+ cells, in contrast to remaining bipotent progenitor cells, which also express Neurog3 mRNA but very low, often undetectable NEU-
ROG3 protein (Villasenor et al. 2008). We therefore investigated if REST inactivation affected the proliferation of discrete NEUROG3-expressing cells. Immunofluorescence analysis of E18.5 Rest ${ }^{p K O}$ pancreas showed that $48.3 \% \pm 6.8 \%$ of NEUROG $3+$ cells coexpressed Ki67 versus $4.6 \% \pm 1.5 \%$ in control embryos $(P<0.01)$ (Fig. 1D). This suggests that REST acts as a negative regulator of cell cycle exit in NEUROG3+ cells, which could contribute in part to the increased number of NEUROG3+ cells in Rest $^{p K O}$ embryonic pancreas.

During embryogenesis, NEUROG3+ cells arise from pancreatic progenitors that form a tubular plexus that progressively evolves into a ductal tree (Gu et al. 2002; Solar et al. 2009; Bankaitis et al. 2015). We tested whether Rest deficiency could not only increase the yield of NEUROG3 + cells during embryonic development but also cause persistent Neurog3 activation in the duct epithelium throughout postnatal life. We therefore examined postnatal (2-wk-old and 12-wk-old) Rest ${ }^{\mathrm{pKO}}$ mice yet found no
A
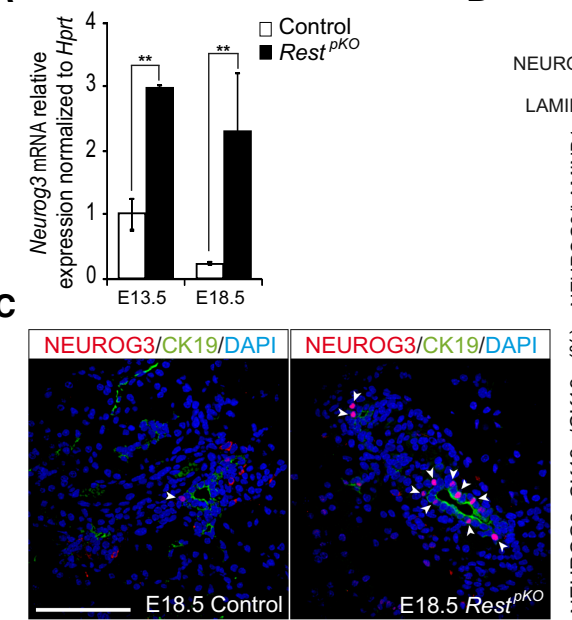

D

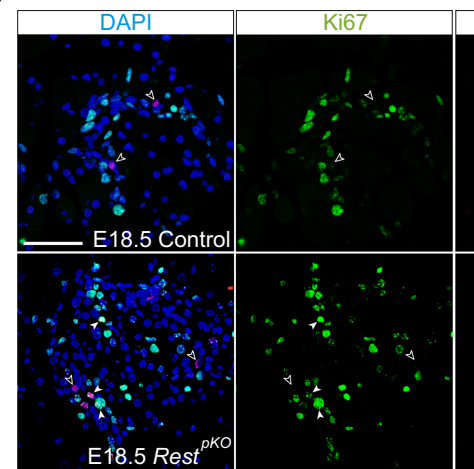

E

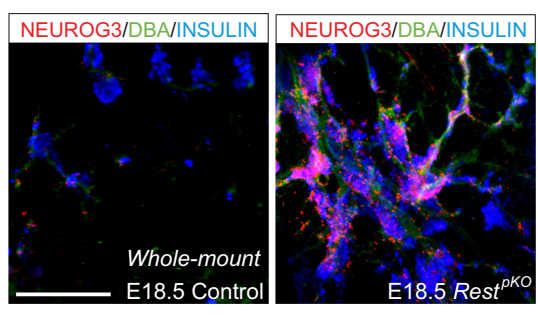

B
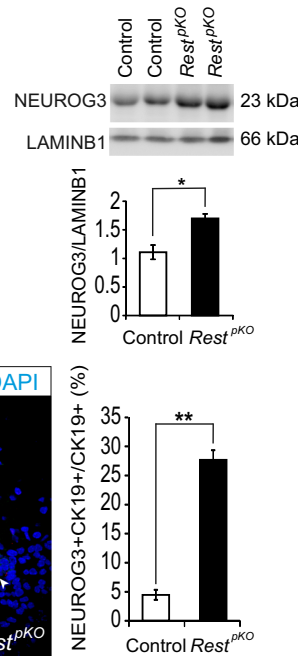

Control Rest ${ }^{p k o}$

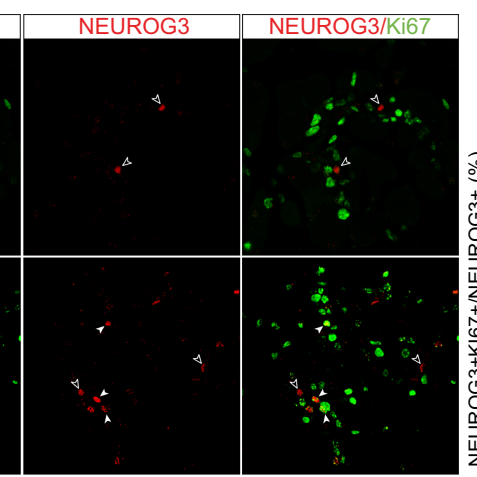

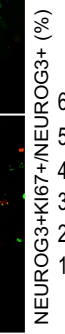

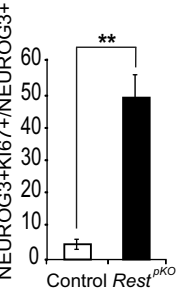

Figure 1. Rest inactivation in pancreatic progenitors induces NEUROG3. (A) Neurog3 mRNA increases in E13 and E18 Rest $^{\mathrm{pKO}}$ pancreas. Normalization by Hprt mRNA; $n=3-4$ mice per group. (B) Western blot and quantifications of NEUROG3 in nuclear extracts from E13.5 control and Rest ${ }^{p K O}$ pancreas. LamininB1 was used as loading control. $n=2$ samples per group with a pull of three E13.5 pancreas per sample. (C) Immunofluorescence for NEUROG3 (red), cytokeratin 19 (CK19; green), and DAPI (blue) in E18.5 control and Rest ${ }^{\mathrm{pKO}}$ pancreas. Arrowheads indicate NEUROG3+ cells. Bars show NEUROG3+ CK19+ cells in E18.5 pancreas. Scale bar, $100 \mu \mathrm{m}$. (D) Immunofluorescence for NEUROG3 (red), Ki67 (green), and DAPI (gray) in E18.5 pancreas. Empty arrowheads indicate NEUROG3+Ki67- cells, and white arrowheads indicate NEUROG3+Ki67+ cells. $n=4-6$ mice per group. Scale bar, $50 \mu \mathrm{m}$. $(E)$ Representative whole mounts for NEUROG3+ (red), DBA (green), and insulin (blue) of the tail of E18.5 control and Rest ${ }^{p K O}$ pancreas. Scale bars, $100 \mu \mathrm{m}$. Error bars are SEM. $\left.{ }^{*}\right) P \leq 0.05,(* *) P \leq 0.01$. 
NEUROG3+ cells (Supplemental Fig. S3). This suggests that additional REST-independent mechanisms are required for persistent Neurog3 activation during postnatal life.

Our studies, therefore, show that REST tempers the yield of NEUROG3+ cells in the embryonic pancreas, in part by suppressing NEUROG3+ cell proliferation. The lack of NEUROG3+ cells in the adult Rest ${ }^{p K O}$ pancreas suggests that REST function is not required to prevent the continuous formation of endocrine progenitor cells from duct cells during postnatal life.

\section{Increased $\beta$-cell mass in mice lacking REST in pancreatic progenitors}

Given that the inactivation of REST in pancreatic progenitors led to the expansion of endocrine-committed NEUROG3+ progenitors, we investigated how this influenced the formation of endocrine cells. Whole-mount stainings for NEUROG3, CK19, and insulin in E18.5 pancreas not only confirmed increased NEUROG3+ cells but also showed a marked increase of the number of insulin-expressing cells (Fig. 1E).

Because the increase in NEUROG3+ cells observed in Rest $^{\mathrm{pKO}}$ pancreas was transient, we investigated whether increased $\beta$-cell mass was maintained in the adult pancreas. Young (12- to 16-wk-old) male Rest ${ }^{p K O}$ mice had normal weight $\left(24.39 \mathrm{~g}_{ \pm} 0.5\right.$ vs. $24.36 \mathrm{~g}_{ \pm} 0.6$ control mice) and fasting glycemia $(49.71 \mathrm{mg} / \mathrm{dL} \pm 1.83$ vs. $54.26 \mathrm{mg} /$ $\mathrm{dL} \pm 3.44$ control mice). Morphometric analysis, however, showed an approximately twofold increase of $\beta$-cell mass in 12 -wk-old Rest ${ }^{\mathrm{pKO}}$ versus control mice, which was primarily owing to an increase of large islets (Student's $t$-test, $P<0.01$ ), as well as an apparent increase in glucagon-expressing cells (Fig. 2A-D). These findings, therefore, showed that inactivation of Rest in pancreatic progenitors results in a transient expansion of NEUROG3+ cells and a sustained increase of pancreatic endocrine cell mass.

\section{REST is a direct regulator of pancreatic endocrine differentiation}

Several genome-wide studies show that REST binds and regulates different genes in different cell types (Bruce et al. 2009; Hwang and Zukin 2018), although REST binding sites have not yet been mapped in pancreas. To study how REST controls pancreatic endocrine differentiation, we identified REST genomic binding sites and REST-dependent transcriptional changes in embryonic pancreatic progenitors. We performed ChIP-seq analysis using a monoclonal antibody (12C11) directed to the REST C-terminal region (Chen et al. 1998), and used chromatin from E13.5 wild-type pancreas, a stage at which REST expression is largely confined to progenitor cells and interspersed mesenchymal cells (Supplemental Fig. S1A). We detected 1968 REST-bound regions (Supplemental Table S1). These were highly enriched in canonical REST recognition motifs, confirming the specificity of REST binding (Supplemental Table S2; Fig. 3A).
The binding properties of repressors are poorly understood. Integration with ATAC-seq profiles from E13.5 pancreas revealed that REST-bound regions were accessible to transposase cleavage yet had an accessibility footprint that was narrower than recognition sites of activating pancreatic transcription factors, plausibly because active regulatory elements are occupied by multiple DNA binding factors (Supplemental Fig. S4).

DNA binding transcription factors that are expressed in multiple cell types often bind to different genomic regions across cell types (e.g., see Servitja et al. 2009), and this has also been observed for REST (Bruce et al. 2009; Hwang and Zukin 2018). We found that 1806 ( 94\%) of REST-bound sites in embryonic pancreas were shared with embryonic stem cells but only $1030(\sim 53 \%)$ with neuronal stem cells (Johnson et al. 2008; Whyte et al. 2012), whereas 91 $(\sim 4.7 \%)$ were exclusively detected in mouse embryonic pancreas (Fig. 3B).

These findings, therefore, defined direct REST-bound regions in early embryonic pancreas. They confirmed that numerous bound regions vary across cell types, although the vast majority are shared with embryonic stem cells (Supplemental Table S3).

To further assess REST function in pancreatic progenitors, we compared RNA-seq profiles of E18.5 Rest ${ }^{\mathrm{pKO}}$ versus control pancreas, a stage at which many progenitors have already been allocated to distinct cellular lineages. We identified 484 down-regulated and 259 upregulated genes in Rest $^{\mathrm{pKO}}$ E18.5 embryonic pancreas (adjusted $P<0.05$ ) (Supplemental Table S4). We found that $29.8 \%$ of up-regulated genes were bound by REST (Fisher $P<10^{-4}$, relative to 15,548 expressed genes), whereas only $9.8 \%$ of down-regulated genes were bound, a similar frequency as all expressed genes $(11.2 \%$; Fisher $P=0.81)$ (Fig. 3C; Supplemental Table S5). This was consistent with the notion that the Rest ${ }^{\mathrm{pKO}}$ phenotype reflects a transcriptional repressor function of REST in the developing pancreas.

REST binds to distal and proximal genomic sites, both of which are likely to harbor functional relevance. However, up-regulated genes in Rest $^{\mathrm{pKO}}$ were most strongly enriched among genes with promoter-proximal REST binding (Fisher $P<10^{4}$ ) (Fig. 3D), which was also observed in early experiments that examined dominant negative inhibition of REST in mouse ESCs (Johnson et al. 2008) Furthermore, REST-bound up-regulated genes were enriched in Polycomb-repressed chromatin in pancreatic progenitors (odds ratio $=3.61$, Fisher $P=7 \times 10^{-4}$ for up-regulated REST-bound genes; odds ratio $=1.12, P=0.75$ for downregulated REST-bound genes; both calculated relative to H3K27me3-enriched genes in PDX1+ E10.5 pancreatic progenitors as defined by van Arensbergen et al. 2010) (Fig. 3E).

Consistent with the increase in endocrine cells in Rest $^{\mathrm{pKO}}$ pancreas, genes that were up-regulated, as well as pancreas REST-bound genes at large, showed a strong enrichment in pancreatic endocrine annotations, including insulin secretion and processing, glucose homeostasis, and endocrine pancreas development (Fig. 3F,G; Supplemental Tables S6, S7). Closer inspection of 

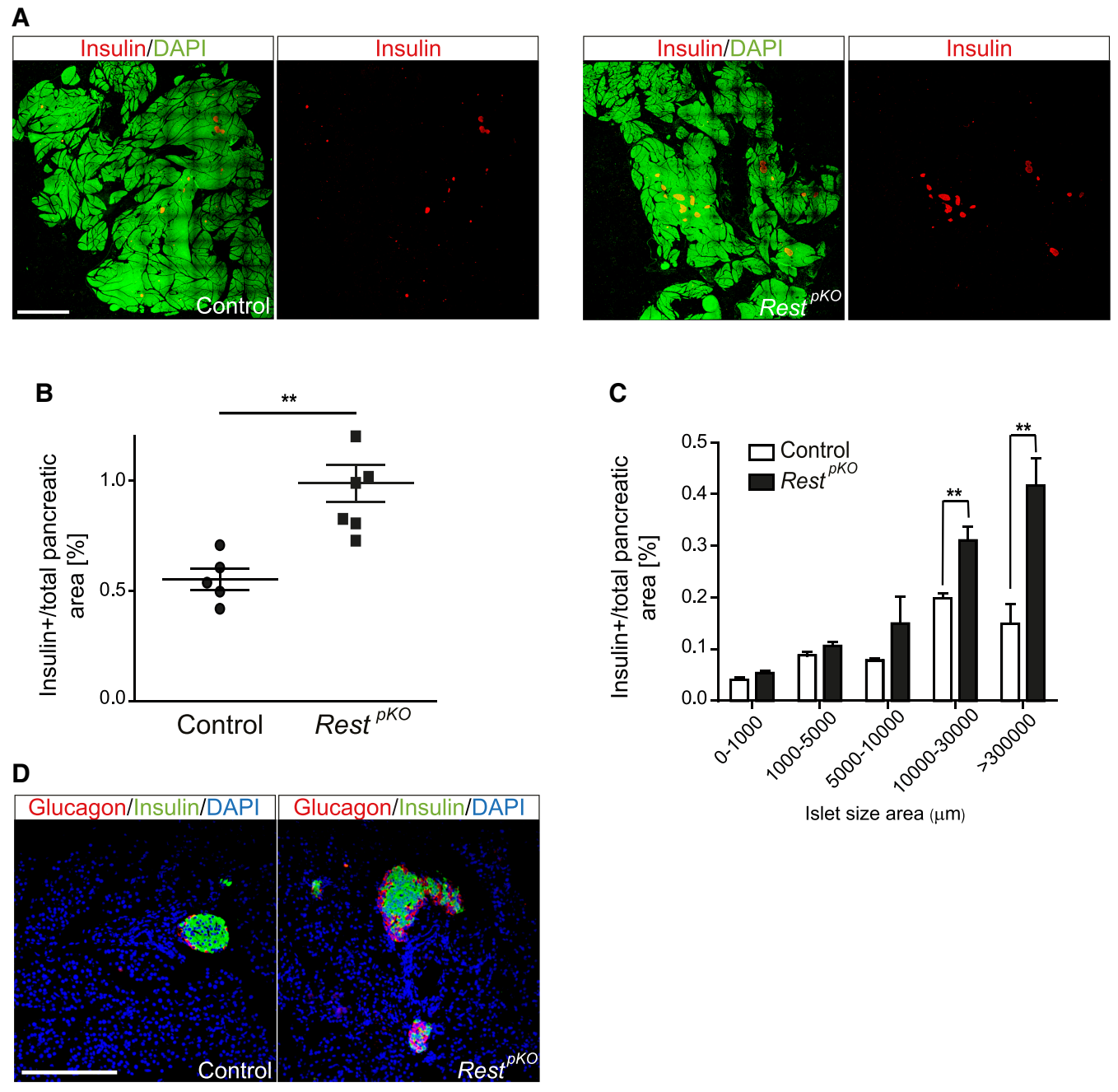

Figure 2. Increased $\beta$-cell mass in Rest ${ }^{\mathrm{pKO}}$ mice. $(A)$ Representative images of $10 \times 10$ frame reconstructions used for $\beta$-cell morphometry of insulin (red) and DAPI (green) stainings in pancreas from 12-wk-old control and Rest ${ }^{\mathrm{pKO}}$ mice. Scale bar, 2 mm. (B) Morphometry of $\beta$ cell mass estimated from insulin surface area/total DAPI surface area (percentage). $R e s t^{\mathrm{pKO}}$ mice have an approximately twofold increase in $\beta$-cell mass. $n=12$ sections from five to six mice in each group. $(C)$ Islet size in control and Rest ${ }^{\mathrm{pKO}}$ adult pancreas. $(D)$ Representative immunofluorescence for glucagon (red), insulin (green), and DAPI (blue) in whole-pancreas from 12-wk-old control and Rest ${ }^{\mathrm{pKO}}$ pancreas. Scale bar, $200 \mu \mathrm{m}$. Error bars indicate SEM. $\left(^{* *}\right) P \leq 0.01$.

individual loci disclosed the location of REST-bound regions at important regulators of pancreatic differentiation (Neurog3, Neurod1, Insm1, Hnf4a, Onecut1, Pax4, Glis3, and Hnf1a), insulin biosynthesis or exocytosis (Pcsk1, Pcsk2, Scg3, Snap25, and Syt7), as well as endocrine cell growth (Bid, Mapk8IP1, Mapk10, and Mapk11) (Fig. 3H; Supplemental Table S3). Regions bound by REST in embryonic pancreas but not in neural or even embryonic stem cells included genes previously associated with pancreatic differentiation and function such as Isl1 (Ahlgren et al. 1997), Prox1 (Paul et al. 2016), or Cdh13 (Supplemental Fig. S5; Tyrberg et al. 2011). Given the increased proliferation of NEUROG3+ cells, it was also interesting to note up-regulation of REST-bound positive cell cycle regulators in Rest ${ }^{\mathrm{pKO}}$, including Cdk5r2, Cdk2ap1, Ccnd1, Mapk3, and Ret (Supplemental Fig. S5; Supplemental Table S5). These studies, therefore, identified direct target genes through which REST controls pancreatic endocrine differentiation programs.

\section{Postnatal inactivation of REST}

Embryonic duct-like bipotent progenitors express many duct cell markers, as well as progressively lose their progenitor capacity as they mature to differentiated duct cells (Solar et al. 2009; Kopinke et al. 2011; Kopp et al. 2011; Bankaitis et al. 2015) REST expression, however, is maintained as embryonic progenitors transition to adult differentiated ductal cells (Supplemental Fig. S1). We therefore asked whether REST inactivation immediately after birth could increase the capacity for de novo generation of endocrine cells. To this end, we used the Hnf $1 b$-CreERT2transgenic line (Solar et al. 2009) to excise the Rest LoxP allele in HNF1B+ cells (most of which are duct cells), and also used 
Rovira et al.

A

\begin{tabular}{|c|c|c|}
\hline De novo Motif Enrichment & $p$-value & $\begin{array}{r}\% \text { of peaks } \\
\text { with motif }\end{array}$ \\
\hline \multirow{2}{*}{ 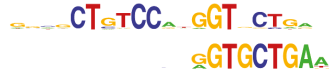 } & 1-e3145 & 65.97 \\
\hline & 1-e474 & 22.08 \\
\hline Known Motif Enrichment & Motif & \\
\hline GGACCTGTCCATGGTSCTGA & REST $1 \mathrm{e}-2960$ & 63.58 \\
\hline
\end{tabular}

B
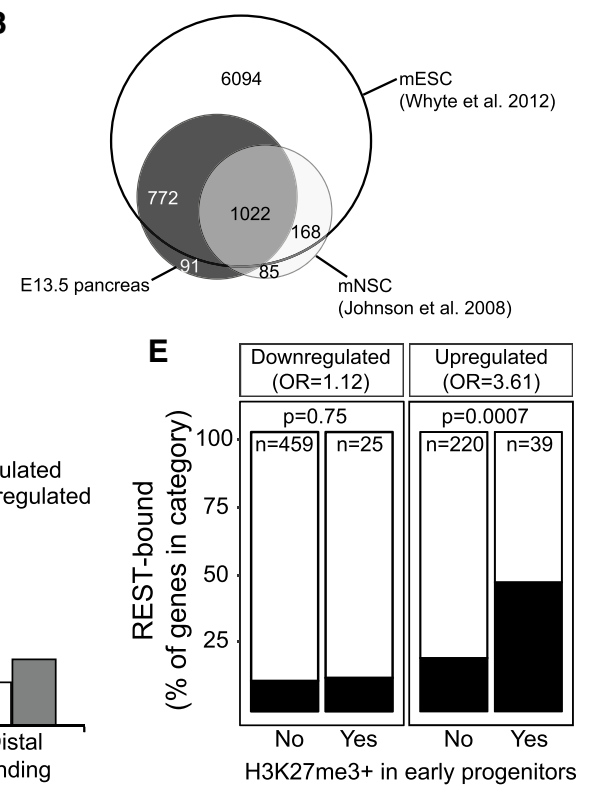

C

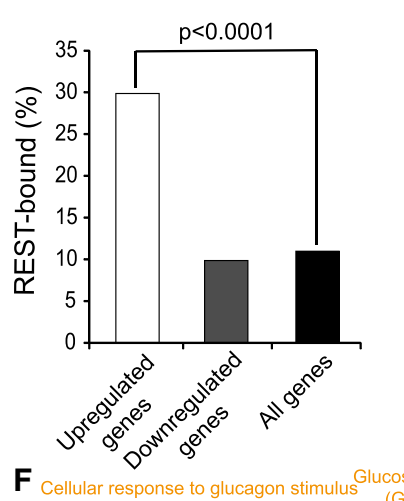

D

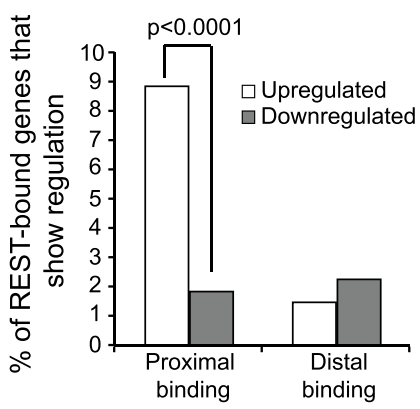

$G_{\text {GSEA Hallmark enrichment }}$

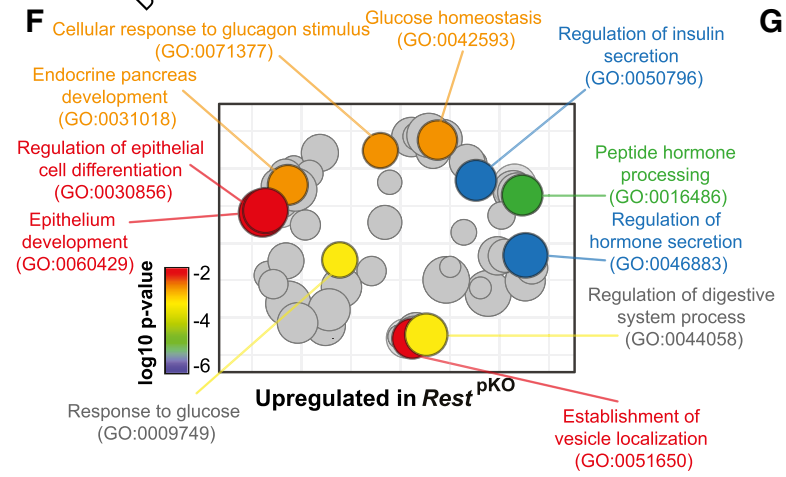
Pancreas Beta FDR GSEA GO enrichment NES FDR

GO Regulation of Hormone Secretion 3.14 0.000 GO Regulation of Hormone Levels $2.89 \quad 0.002$ GO Regulation of Peptide Secretion $2.85 \quad 0.003$
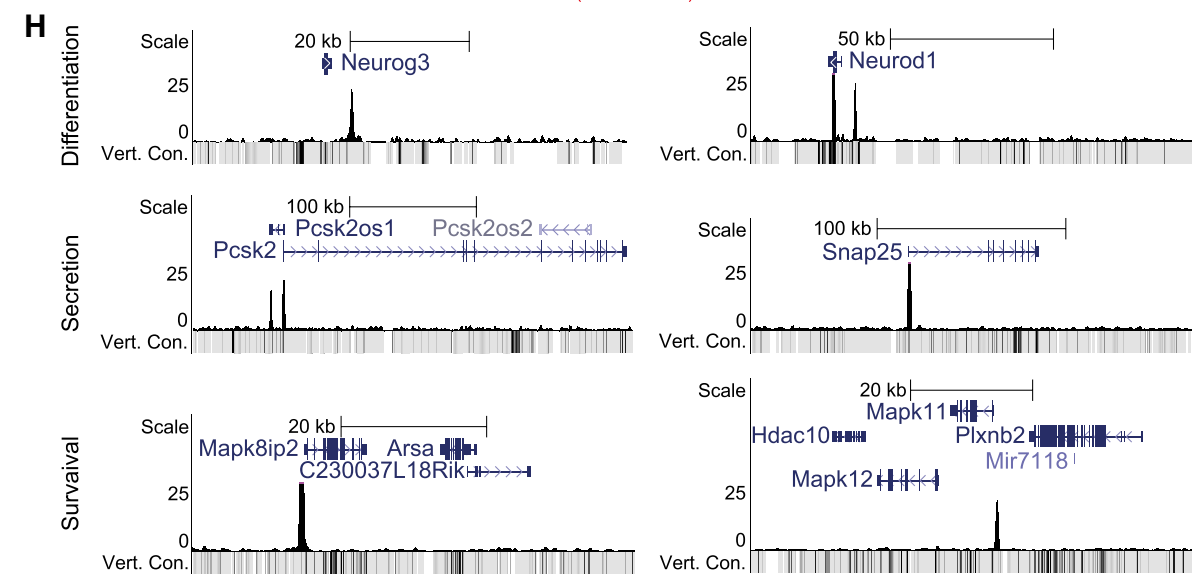

Figure 3. Functional direct REST targets in the embryonic pancreas. (A) Top de novo and known motif enrichments in REST-bound regions. (B) REST-bound regions in E13.5 pancreas, mESCs, and mNSCs. (C) Percentage of up-regulated and down-regulated genes in Rest ${ }^{\mathrm{pKO}}$ mice, or all genes, that were bound by REST. Results indicate that REST predominantly acts as a repressor. $P$-values are Fisher exact test. $(D)$ REST binds preferentially to promoter-proximal (0- to 5-kb) regions of genes that were up-regulated in Rest ${ }^{\mathrm{pKO}}$ mice. $(E)$ Percentage of differentially expressed genes that were bound by REST, broken down by H3K27me3 enrichment in purified pancreatic progenitors in (van Arensbergen et al. 2010). REST binding was enriched in genes that were up-regulated in Rest $\mathrm{t}^{\mathrm{pKO}}$ and showed H3K27me3 in progenitors. $P$ values from Fisher exact test. $(F)$ Up-regulated genes were functionally annotated using Gorilla (Eden et al. 2009), and REVIGO (Supek et al. 2011) was used to visualize annotation clusters. The most significant terms are highlighted according to a $P$-value color scale. (G) Significant GSEA terms for up-regulated genes. $(H)$ REST binding associated to pancreatic endocrine development (Neurog3 and NeuroD1), insulin secretion (Snap25 and Pcsk2), and $\beta$-cell survival (Mapk11 and Mapk8ip2) genes in E13.5 pancreas. Y-axes are -log 10 -values. The vert. cons. track depicts vertebrate conservation. 
a Rosa26-LSL-RFP reporter (Luche et al. 2007) to trace the progeny of cells that have undergone Rest excision (Fig. 4A). We treated dams of triple transgenic newborns (hereafter called Rest ${ }^{\mathrm{dKO}}$ Rosa26 $^{\mathrm{RFP}}$ ) or Hnf1b-CreERT2; Rosa26 ${ }^{\mathrm{RFP}}$ controls with tamoxifen at postnatal days 1 and 3 and then analyzed mice after weaning (Fig. 4B). This showed that the number of insulin+/RFP+ and glucagon $+/$ RFP+ cells was increased 5.3 -fold \pm 0.5 -fold and 6.4fold \pm 1.6 -fold (Student's $t$-test $P<0.01$ ), respectively, in Rest $^{\text {dKO }}$ mice relative to $H n f 1 b$-CreERT2; Rosa $26^{\text {RFP }}$ control mice (Fig. 4C). These results indicate that although the inactivation of REST in embryonic pancreatic progenitors did not result in persistent activation of endocrine progenitor markers throughout adult life, induced inactivation of REST in neonatal pancreas did transiently increase endocrine cell formation.
In contrast, REST inactivation in pancreatic duct cells from $12 \mathrm{wk}$ olds using the same lineage tracing model did not lead to significantly increased number of insulin $+/$ RFP + cells 4 wk after induction $(2.54 \% \pm 0.33 \%$ in Rest $^{\mathrm{dKO}}$ Rosa2 $^{\mathrm{RFP}}$ vs. $1.96 \% \pm 0.49 \%$ in control mice; Student's $t$-test, $P=0.177$ ) (Supplemental Fig. S6). Thus, although REST retains an essential function to suppress endocrine cell formation in early postnatal periods, this role subsides in adult mice, consistent with a more limited differentiation potency of mature duct cells.

\section{Chemical inhibition of REST in zebrafish}

Encouraged by the observation that inactivation of REST in early postnatal duct cells increased the de novo generation of endocrine cells, we explored whether similar
A

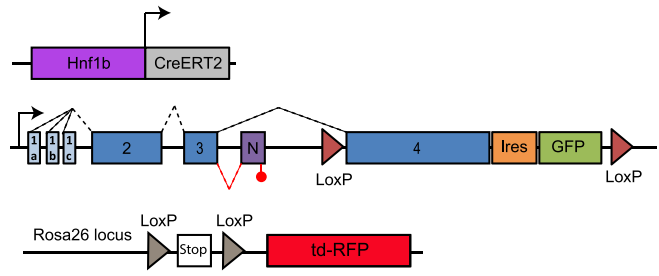

B

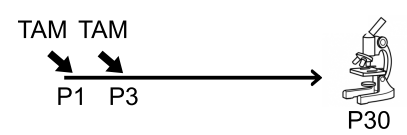

C

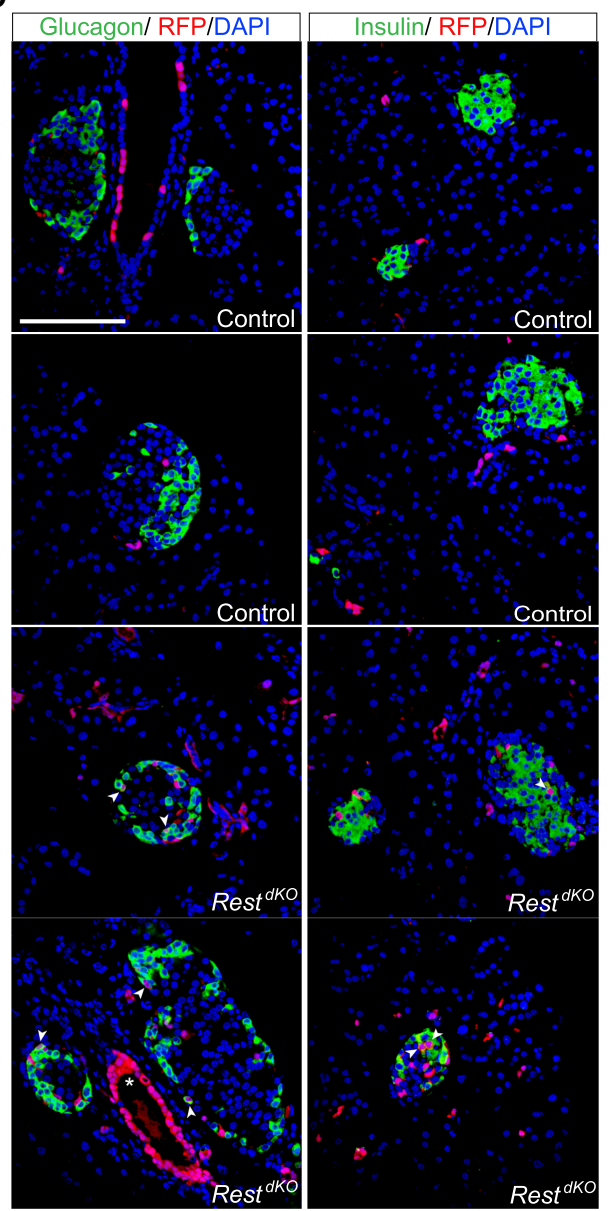

Figure 4. Pancreas-specific inactivation of Rest in neonatal ducts. (A) Schematic of genetic models used to inactivate Rest and activate RFP expression in duct cells and progeny. Hnf1b-CreERT2 is a BAC transgenic that specifically marks duct cells (Solar et al. 2009), as well as non-Rest-expressing $\partial$ cells in reporters that are excised with high efficiency (Rovira et al. 2021), but not other endocrine or acinar cells. $(B)$ Schematic of the lineage tracing experiment. Tamoxifen was given to mothers at day 1 (P1) and day 3 (P3) after delivery, and mice were analyzed at P30. Hnf1b-CreERT2; Rosa26 ${ }^{\mathrm{RFP}}$ control mice were also treated. (C) Representative images of double-positive RFP (red) and insulin (green) cells and of double-positive RFP (red) and glucagon (green) cells in Rest ${ }^{\mathrm{dKO}}$ and control mice. The graph shows RFP-expressing glucagon and insulin cells in Rest ${ }^{\mathrm{dKO}}$ versus control mice. $n=5-6$ mice per each group. Arrowheads indicate double-positive cells, and an asterisk marks examples of cells in a duct, which were very efficiently labelled. Scale bar, $100 \mu \mathrm{m}$. Error bars are SEM. Student's $t$-test; $\left({ }^{* *}\right) P<0.01$. 
effects could be extended to other model systems using chemical inhibition of REST. We used X5050, recently identified in a high-throughput screen to inhibit REST by protein destabilization (Charbord et al. 2013).

To study REST function in zebrafish, we used a double transgenic line in which glucagon- and insulin-expressing cells show green and red fluorescence, respectively (Ins: mcherry/Gcga:gfp). We treated zebrafish embryos at 3 dpf with X5050 for $3 \mathrm{~d}$ or with the Notch inhibitor DAPT as a positive control (Parsons et al. 2009), and at 6 dpf, we dissected the pancreas to quantify secondary islet formation as a readout for endocrine cell differentiation.
Secondary islets are normally apparent in $~ 10 \%$ of control larvae at $5 \mathrm{dpf}$, and this percentage increases gradually thereafter (Parsons et al. 2009). Compared with DMSO controls, X5050-treated 6-dpf embryos displayed a dosedependent increase in secondary islet formation $(5 \mu \mathrm{M}$ and $50 \mu \mathrm{M}$ : 2.2-fold \pm 0.4 -fold and 3.5-fold \pm 0.1 -fold increase; SD, Student's $t$-test $P<0.05$ and $P<0.01$, respectively), which was comparable with $50 \mu \mathrm{M}$ DAPT (4.2fold \pm 0.4 -fold, $P<0.01$ ) (Fig. 5A). These results suggest that REST regulation of pancreatic endocrine differentiation is conserved in zebrafish and that this process can be manipulated through chemical inhibition.
A
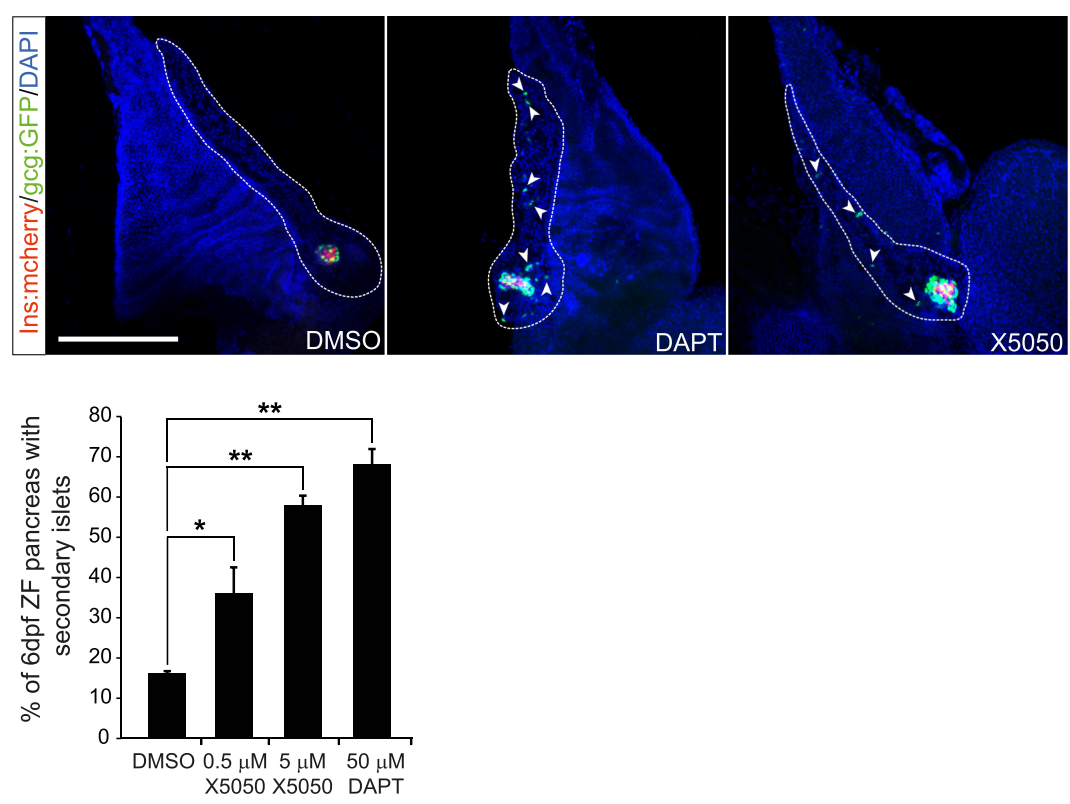

B
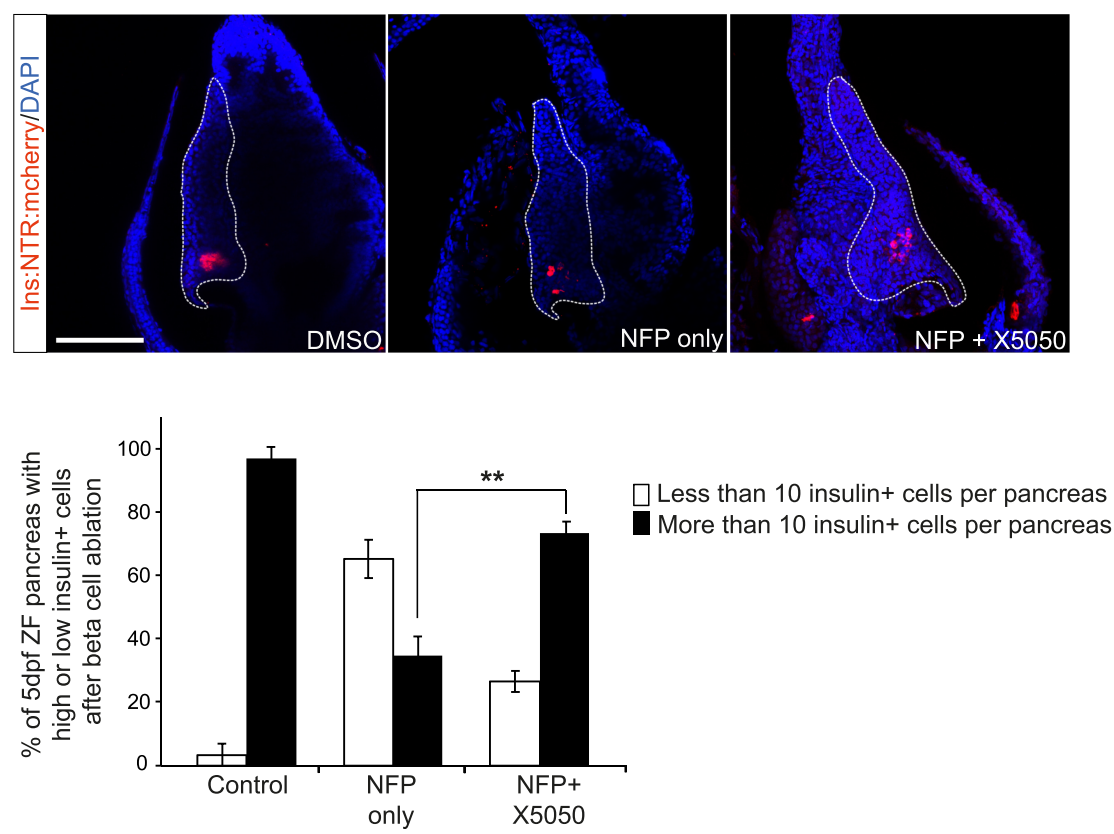

Figure 5. REST regulation of endocrine differentiation is conserved in zebrafish. $(A)$ Embryos of Ins:mCherry/Gcga:GFP doubletransgenic zebrafish line treated with 50 $\mu \mathrm{M}$ DAPT (Notch inhibitor used as positive control), 0.5 or $5 \mu \mathrm{M}$ X5050, or vehicle (DMSO, negative control) from 3 dpf until 6 dpf. After drug treatment at $6 \mathrm{dpf}$, zebrafish pancreas was dissected, and the presence or absence of secondary islets was quantified. Arrows show representative secondary islets of double-transgenic zebrafish embryos (Ins: mCherry/Gcga:GFP; [blue] DAPI). The graph shows the percentage of zebrafish with detectable secondary islets in each condition. $n=20-25$ fish per each condition. $(B)$ An Ins:NTR-mCherry line was used to selectively ablate $\beta$ cells upon treatment with 5 $\mu M$ nifurpirinol (NFP) (Pisharath et al. 2007; Bergemann et al. 2018) in 3-dpf embryos; $24 \mathrm{~h}$ later after complete $\beta$-cell ablation of the principal islet, embryos were exposed to $5 \mu \mathrm{M} \times 5050$ or vehicle, and $\beta$ cells were analyzed 36 h later. Representative images of $\beta$ cell regeneration in Ins:NTR-mCherry embryos treated with vehicle (DMSO), with NFP only, or with NFP and X5050. (Red) Insulin, (blue) DAPI. The graph shows the percentage of pancreas showing $>10$ insulinexpressing cells in every condition. $n=32$ 36 fish per each condition. Scale bars, 200 $\mu \mathrm{m}$. Error bars are SEM. $\left(^{* *}\right) P<0.01,\left(^{*}\right) P<$ $0.05, \chi^{2}$ test. 
We next investigated whether REST inhibition could accelerate $\beta$-cell neogenesis after $\beta$ ablation with nifurpirinol (NFP), using Ins:NTR-mcherry transgenic zebrafish (Bergemann et al. 2018). In this model, 3-dpf embryos are treated with NFP, causing ablation of $>95 \%$ of $\beta$ cells in $24 \mathrm{~h}$ and full recovery of $\beta$-cell mass in 48-72 $\mathrm{h}$ (Bergemann et al. 2018 ). We note that at $3 \mathrm{dpf}$, all $\beta$ cells form part of principal islets. After washing NFP, we ascertained complete $\beta$-cell ablation with a stereomicroscope and then treated embryos with X5050 or vehicle, and $36 \mathrm{~h}$ later, we examined which embryos had recovered $>10 \beta$ cells, a threshold that enables unequivocal distinction from complete ablation. We observed that $73.4 \% \pm 3.3 \%$ of X5050-treated embryos showed $>10$ insulin-positive cells in the principal islet, whereas this was only seen in $34.7 \% \pm 6.1 \%$ of controls (mean and SD of 34-38 embryos in each group, $\chi^{2}$ test, $P<0.01$ ) (Fig. 5B). Thus, REST inhibition promoted $\beta$-cell formation in a zebrafish embryo regeneration model.

\section{REST inhibition in human organoids}

We next explored the impact of REST manipulation in human cells. We first validated that 24 -h treatment of an immortalized duct cell line (PANC-1) with X5050 caused an $\sim 50 \%$ reduction of REST full-length protein, as well as a relative increase in the REST4 isoform, as previously described (Fig. 6A; Charbord et al. 2013). Next, we studied ex vivo organoid cultures from human adult ducts isolated from the exocrine fraction of the pancreas of cadaveric donors. Organoids were generated and expanded as previously described (Boj et al. 2015), and experiments were performed at passages 3-4 (Fig. 6B). Currently, the efficiency of endocrine differentiation from published ex vivo pancreas organoid protocols is still limited (Huch et al. 2013; Boj et al. 2015; Loomans et al. 2018). We thus investigated if REST inhibition in pancreatic human organoids could promote the activation of pancreatic endocrine lineage genes. We treated human organoids with X5050 for $48 \mathrm{~h}$ and observed only rare endocrine cells in treated and nontreated organoids. However, X5050-treated organoids showed induction of INS, NEUROG3, and PDX1 mRNA levels (2.27-fold \pm 0.43 -fold, 3.18-fold \pm 1.06 -fold, and 2.18 -fold \pm 0.54 -fold increased vs. DMSO, respectively; SD, Student's $t$-test, $P<0.01$ ), whereas the duct cell marker SOX 9 mRNA did not change (Fig. 6B). These results therefore show that chemical interference of REST in adult human pancreas organoids did not lead to $\beta$-cell formation, consistent with genetic findings in adult mice, although it induced the transcription of endocrine genes.

\section{Discussion}

Despite early suggestions that REST could be important for pancreatic endocrine differentiation during embryonic
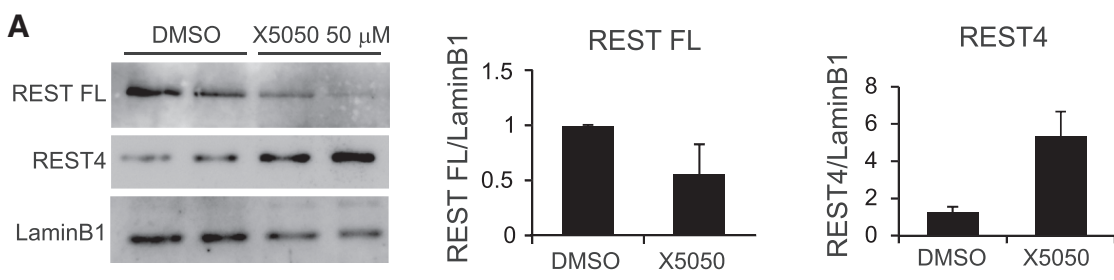

B

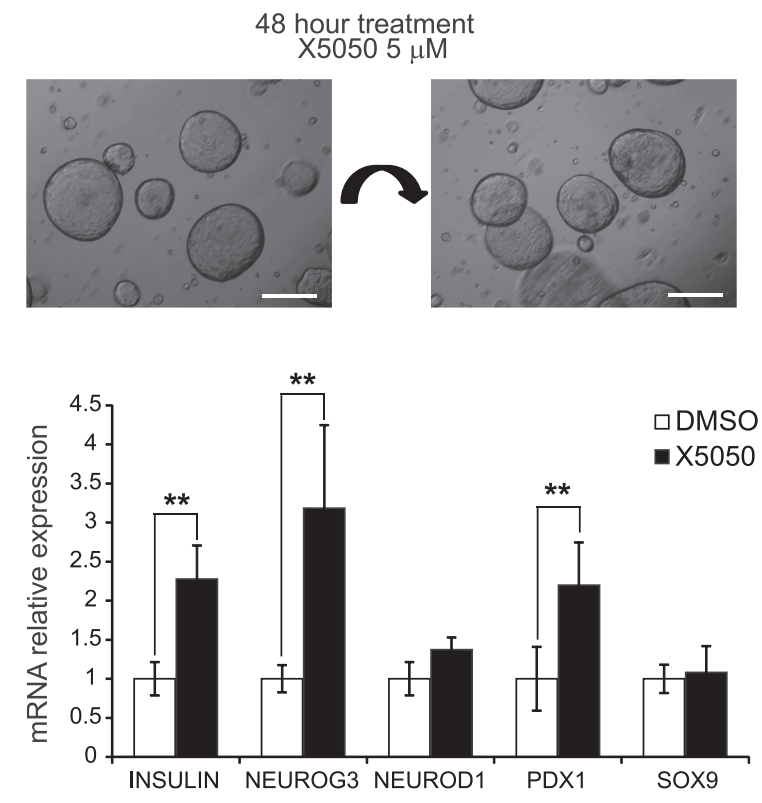

Figure 6. REST chemical inhibition in human pancreatic organoids. $(A)$ Western blot analysis of REST FL (full-length) and REST4 protein levels in PANC1 cells treated with X5050 $50 \mu \mathrm{M}$ or DMSO (control). (Lamin B1) Loading control. Bar plot shows the quantification of the Western blot for REST. (B) Human organoids generated from pancreatic exocrine fractions from two cadaveric donors were treated at passage 3 for $48 \mathrm{~h}$ with $5 \mu \mathrm{M}$ X5050 or DMSO (control vehicle). qPCR analysis of mRNA for indicated genes, relative to TBP. Scale bars, $200 \mu \mathrm{m}$. Error bars are SD. Student's $t$-test, $\left(^{* *}\right) P<0.01$. 
development (Martin et al. 2008, 2012; van Arensbergen et al. 2010), conditional ablation of Rest in the mouse pancreas unexpectedly showed modest gene expression differences and no quantitative changes in endocrine cell formation (Martin et al. 2015). This result clearly did not suggest a major regulatory role in pancreas endocrinogenesis. We have now combined genetic and chemical perturbations to show that REST plays a key evolutionary conserved role to modulate the generation of endocrine cells during pancreas organogenesis. We define for the first time a blueprint of direct REST target genes in the embryonic pancreas that underpin this regulatory function. We further show that the capacity to increase endocrinogenesis upon REST inactivation in duct cells decreases during postnatal life, whereas REST inhibition in human adult pancreas organoids influenced expression of endocrine genes but did not trigger endocrine cell formation. These findings therefore establish REST as an important regulator of endocrinogenesis during embryonic pancreas development.

During pancreas development, a subset of HNF1B+ duct-endocrine bipotent progenitors that form a tubular plexus trigger an endocrine gene program, whereas others give rise to mature ductal cells (Solar et al. 2009; Bankaitis et al. 2015). The mechanisms that underlie this binary lineage choice in a seemingly uniform pool of progenitors is unclear. Our results suggest that REST restrains the frequency with which bipotent progenitors consolidate an endocrine vs. duct fate. On the other hand, the fact that REST deficiency did not cause an en masse conversion of bipotent progenitors into endocrine cells is consistent with the notion that REST is not the sole guardian of endocrine differentiation but instead acts in concert with other positive and negative regulators to define a differentiation probability.

Genetic experiments have indeed revealed numerous transcriptional regulators that promote pancreatic endocrine cell formation, including NKX6-1, NKX2-2, NEUROG3, HNF1B, and INMS1, among others (Sussel et al. 1998; Gradwohl et al. 2000; Osipovich et al. 2014; De Vas et al. 2015). Among DNA binding factors that suppress endocrinogenesis, Hippo-responsive TEAD-YAP complexes are an integral component of pancreatic multipotent progenitor enhancers and plausibly counteract endocrine differentiation by promoting a progenitor transcriptional state (Cebola et al. 2015; Mamidi et al. 2018; Rosado-Olivieri et al. 2019). Notch-responsive transcriptional repressors, notably HES1, bind near endocrine genes, where they are likely to exert direct transcriptional repression (Jensen et al. 2000; de Lichtenberg et al. 2018). An important unsolved question is how REST interplays with such inhibitory and positive regulators at different stages to ensure a timely and balanced generation of endocrine cells.

The inhibitory function of REST has potential implications for efforts to enhance endocrinogenesis in various in vivo or in vitro settings. Current pancreas organoid models are limited because existing protocols largely recapitulate exocrine cell expansion. On the other hand, our experiments showed that REST derepression enhanced endocrinogenesis in embryonic progenitors and even early postnatal pancreas but was clearly less efficient in the adult differentiated pancreas. This may mean that REST restrains endocrine differentiation in progenitors that express positive endocrine regulators and have the appropriate epigenetic competence, whereas mature duct epithelial cells may lack these properties. Nonetheless, the observation that REST inhibition did elicit increased expression of islet endocrine genes in human exocrine organoids, together with the recent observation that it can enhance transcription factor-mediated reprogramming of mouse adult exocrine cells (Elhanani et al. 2020), suggests that REST modulators may form part of an arsenal for future manipulations to promote endocrinogenesis in experimental model systems or replacement therapies.

\section{Materials and methods}

Mouse models

All experiments were approved by the Institutional Animal Care Committee of the University of Barcelona. Mice with Rest exon 4 floxed allele (Rest ${ }^{L S L}$ ) (Yamada et al. 2010) were crossed to Pdx1Cre (Gu et al. 2002) or Hnf1b-CreERT2 (Solar et al. 2009) and Rosa26-LSL-RFP transgenic lines (Luche et al. 2007). We also generated Rest ${ }^{L S L}$ mice carrying a different $P d x 1$-Cre transgene (Hingorani et al. 2003) and confirmed increased endocrine cell mass in adult mice as well as increased NEUROG3+ cells at E18.5. To induce recombination in triple transgenics (Hnf1b-CreERT2; Rosa26RFP;Rest ${ }^{\mathrm{LSL}}$ or Hnf1b-CreERT2;Rosa26 ${ }^{\mathrm{RFP}}$ control mice), $20 \mathrm{mg}$ of tamoxifen (Sigma T5648) was administered by gavage to the mother at days 1 and 3 after delivery. Mice were then sacrificed at $30 \mathrm{~d}$ of age. For adults, tamoxifen was given by gavage in three doses $(20 \mathrm{mg}, 20 \mathrm{mg}$, and $10 \mathrm{mg}$ ) over 1 wk to 8 - to 12 -wkold mice, and mice were analyzed $4 \mathrm{wk}$ later. Oligonucleotides used for genotyping are in Supplemental Table S8.

Dissociation and FACS analysis of pancreatic cells

Adult and E18.5 mouse pancreas from Sox9-eGFP transgenics (Gong et al. 2003) were digested in $1.4 \mathrm{mg} / \mathrm{mL}$ collagenase-P (Roche) for $20-30 \mathrm{~min}$ at $37^{\circ} \mathrm{C}$. Peripheral acinar-ductal units, depleted of endocrine islets, were prepared as previously described (Wang et al. 2013). Tissue was filtered through 600- $\mu \mathrm{m}$ and 100$\mu \mathrm{m}$ polypropylene meshes (BD), and peripheral acinar-ductal units were further dissociated in diluted TrypLE (Invitrogen) for $5 \mathrm{~min}$ at $37^{\circ} \mathrm{C}$. Dispersed cells were filtered through a $40-\mu \mathrm{m}$ polypropylene mesh $(\mathrm{BD})$ before FACS sorting.

\section{Immunoblots}

Nuclear extracts were prepared as previously described (Maestro et al. 2003) and separated on a 7\% SDS-PAGE gel and transferred to an Immobilon polyvinylidene difluoride membrane (Millipore). Immunodetection was performed with mouse $12 \mathrm{C} 11$ anti-REST (1:1000) or rabbit anti-LaminB1 (1:2000; Cell Signaling). Quantification was performed with ImageJ-Fiji.

RNA analysis

RNA was isolated using the RNeasy minikit (Qiagen) or TRIzol followed by DNase I treatment (Invitrogen). RNA was reverse- 
REST inhibits pancreas endocrine differentiation

transcribed with SuperScript III reverse transcriptase (Roche) and random hexamers, and qPCR was performed on a 7900 real-time PCR system (Applied Biosystems) using Power SYBR green (Applied Biosystems). Oligonucleotides are shown in Supplemental Table S8.

RNA-seq

DNase-treated RNA (RIN > 8) was generated from three E18.5 pancreas for each genotype and used for 100-bp paired-end read Illumina sequencing. Reads were aligned to the NCBI36/mm9 genome using STAR (v2.3.0) (Dobin et al. 2013) with default parameters, allowing only uniquely mapped reads. The resulting bam files were used to quantify gene expression using FeatureCounts (v1.5) using UCSC mm9 reference gene annotations. Differential expression analysis was performed using DESeq2 (Love et al. 2014) using an adjusted $P$-value $<0.05$ cutoff.

\section{ChIP-seq}

ChIPs were from dissected E13.5 pancreatic buds and were performed as described by van Arensbergen et al. $(2010,2013)$.

ChIP DNA (1-2 ng) from two independent pools of E13.5 pancreas were used for ChIP sequencing of single-end 50-bp reads. Reads were aligned to NCBI $36 / \mathrm{mm} 9$ genome using Bowtie2 (v2.2.5) allowing for one mismatch. Bam files were filtered to retain reads with a MAPQ $\geq 10$. Bam files from biological replicates were pooled using samtools, and peaks were called using MACS2 (v2.1.0) using default parameters. Input DNA was used to define significant peaks at a false detection rate of $<0.05$.

Functional gene annotations

GSEA was performed in preranked lists and analyzed with 1000 permutations. Differentially expressed genes were functionally annotated using Gorilla (Eden et al. 2009), and REVIGO (Supek et al. 2011) was used to visualize most significant terms in each GO cluster.

\section{ATAC-seq profiles around transcription factor binding sites}

To plot ATAC-seq profiles around transcription factor binding sites (TFBSs), we conducted footprinting with HINT from the RGT library (v0.13.1) (Li et al. 2019). An ATAC-seq model and paired-end data were specified for tool execution, using aligned read BAM files and ATAC-seq peaks in BED format. Once footprints were called, overlapping TFBSs were found using the RGT-matching motif tool and the complete JASPAR motifs database. For REST (MA0138.2), we selected only footprints overlapping a REST ChIP-seq peak using ChIPpeakAnno (v3.18.1), GenomicRanges (v1.36.0), and Bioconductor (v3.9.0) R (v3.6.3) and lifting to mm10. Normalized ATAC-seq profiles around TFBSs of interest were generated with HINT for a 500-bp window size, enabling ATAC-seq bias correction.

\section{REST binding enrichment in differentially expressed genes}

Genomic regions were associated with genes using GREAT v3.0, applying default parameters to the basal plus extension association rule (McLean et al. 2010). Proximal and distal REST-bound regions were defined as $<5 \mathrm{~kb}$ or $>5 \mathrm{~kb}$ from the transcriptional start sites, respectively. REST-bound genes were annotated based on H3K27me3 enrichment (van Arensbergen et al. 2010).
Motif analysis

De novo and known motifs of REST-bound regions were analyzed with HOMER, using a 500-bp window centered on the REST peak.

\section{Immunolocalization methods}

Paraffin-embedded pancreas were processed for immunolocalization as described by Maestro et al. (2003). Whole-mount staining of E18.5 pancreas was performed as previously described (Ahnfelt-Rønne et al. 2007) without TSA amplification. For $\beta$-cell mass measurements in 3-mo-old mice, 4- $\mathrm{um}$ sections were obtained at $150-\mu \mathrm{m}$ intervals, and $21-24$ sections per pancreas were analyzed by immunofluorescence for insulin and DAPI. Images were taken by automated capturing and reconstruction of 10 $\times 10$ frames using a Leica SP confocal microscope. Insulin-positive and total tissue areas (measured by DAPI saturation) were determined by ImageJ. Islet size distribution was quantified with an automated ImageJ plugin. Antibodies are shown in Supplemental Table S9.

\section{Human organoid culture}

Human exocrine tissue, obtained from the discarded fraction after human islet purifications from cadaveric organ donors (Gmyr et al. 2000), was used only if islets were insufficient for clinical transplantation and if scientific research was granted according to national French regulations. Ethical approval for processing pancreatic samples from deidentified organ donors was granted by the Clinical Research Ethics Committee of Hospital Clinic de Barcelona (HCB/2014/0926 and HCB/2014/1151).

Tissues were minced and digested with $5 \mathrm{mg} / \mathrm{mL}$ collagenase II (Gibco) in human complete medium for $30 \mathrm{~min}$ to $1 \mathrm{~h}$ at $37^{\circ} \mathrm{C}$. The material was further digested with TrypLE (Gibco) for 5 min at $37^{\circ} \mathrm{C}$, embedded in GFR Matrigel (Kerr Conte et al. 1996), and cultured in human organoid expansion medium (Boj et al. 2015). After three passages, we treated organoids with $\mathrm{X} 5050$ (Calbiochem) in human complete media for $48 \mathrm{~h}$ before RNA analysis.

\section{Zebrafish studies}

Tg(gcga:GFP), Tg(T2KIns:hmgb1-mcherry), and Tg(ins:NTR$m$ Cherry) were obtained from Isabelle Mandfroid (University of Liege, Belgium) (Parsons et al. 2009; Bergemann et al. 2018). Double-transgenic Tg(gcga:GFP)/Tg(T2KIns:hmgb1-mCherry) embryos were incubated from $3 \mathrm{dpf}$ to $6 \mathrm{dpf}$ at $28^{\circ} \mathrm{C}$ in the dark in $50 \mu \mathrm{M}$ DAPT (Tocris) and 0.5 and $5 \mu \mathrm{M}$ X5050 (Calbiochem) (Charbord et al. 2013) or 1\% DMSO in E3 (Parsons et al. 2009). Zebrafish were then fixed overnight in $4 \%$ paraformaldehyde; pancreas was dissected for confocal image analysis.

$\mathrm{Tg}$ (Ins:NTR-mCherry) was used for $\beta$-cell ablation studies upon treatment with $5 \mu \mathrm{M}$ nifurpirinol (NFP) (Bergemann et al. 2018) in 3 -dpf embryos. In this model, $24 \mathrm{~h}$ after NFP treatment, $>95 \%$ of the $\beta$ cells are ablated and $\beta$-cell mass recovered in $48-72 \mathrm{~h}$ (Parsons et al. 2009; Bergemann et al. 2018). NFP-treated embryos were washed and treated with $5 \mu \mathrm{M}$ X5050 or DMSO. $\beta$-Cell regeneration was analyzed after $36 \mathrm{~h}$. After drug treatment, 5-dpf zebrafish were fixed overnight in $4 \%$ paraformaldehyde, and pancreas was dissected for confocal image analysis.

To microdissect pancreas, fixed embryos were placed in PBS on an agarose-lined plate. Then, using pulled capillaries as tools, first the yolk and then the whole foregut were pried away from the embryo. The pancreas was placed islet-down on a coverslip and dried by removing all excess PBS. This coverslip was then mounted 
onto a microscope slide. Water was introduced under the cover slip to rehydrate the sample.

Confocal Z-series stacks were acquired on a Leica SP5 confocal microscope. Maximum projections were obtained by LAS AF software. To count endocrine cells, we used a double-transgenic line. Tg(gcga:GFP) and Tg(T2KIns:hmgb1-mCherry), where glucagon-positive cells were green and insulin-positive cells were red. Upon maximum projections of Z-series of the entire pancreas, the presence or absence of secondary islets was computed.

\section{Statistics}

Statistical analyses were performed using either R or GraphPad Prism 6. Statistical significance was calculated with a Fisher exact test or an unpaired, two-tailed Student's $t$-test with data expressed as mean \pm SEM unless otherwise specified. $P$-values < 0.05 were considered significant.

Data availability

ChIP-seq and RNA-seq data sets are available in GSE179120.

\section{Competing interest statement}

The authors declare no competing interests.

\section{Acknowledgments}

We thank the University of Barcelona School of Medicine animal facility and National Institute for Health Research Imperial Biomedical Research Centre Genomics Unit and Cristina García for zebrafish support and maintenance. We thank Isabelle Manfroid (University of Liège) for generous sharing of the zebrafish lines and Irene Miguel-Escalada, Anthony Beucher, and Inês Cebola for critical comments on the manuscript. This research was supported by Ministerio de Ciencia, Innovación y Universidades (SAF2015-73226-JIN [Agencia Estatal de Investigación $\{\mathrm{AEI}\} /$ European Regional Development Fund, European Union \{UE\}] and RYC-2017-21950 [AEI/European Social Fund, UE] to M.R., and BFU2014-54284-R and RTI2018-095666-B-I00 to J.F.); the Medical Research Council (MR/L02036X/1), Wellcome Trust (WT101033), and European Research Council Advanced Grant (789055) (to J.F.); the Instituto de Salud Carlos III (CA18/00045 to J.L.M.); and a Spanish Ministry of Science, Innovation, and Universities (MCIU) fellowship (PTA2018-016371-I to M.M.). J.K.-C.'s and F.P.'s research was supported by L'Agence Nationale de la Recherche (ANR) grants, L'Institut Européen de Génomique du Diabète (EGID), ANR-10-LABX-0046, a French state fund managed by ANR under the frame program Investissements d'Avenir (I-SITE ULNE/ANR-16-IDEX-0004 ULNE to F.P.), and the European Consortium for Islet Transplantation funded by the Juvenile Diabetes Research Foundation International. Work in the Centre for Genomic Regulation was supported by the Centres de Recerca de Catalunya (CERCA) Programme, Generalitat de Catalunya, and Centro de Excelencia Severo Ochoa (SEV2015-0510). Work at Institut d'Investigació Biomèdica de Bellvitge was supported by the CERCA Programme and Generalitat de Catalunya.

Author contributions: M.R. and J.F. conceived and coordinated the study. M.R. performed mouse, organoid, zebrafish, and computational studies. M.R. and M.A.M. performed image analysis of mouse mutants. G.A, M.M., and J.L.M performed computational analysis. V.G. maintained mouse colonies and performed morphometry studies. J.G.-H. performed ChIP experiments and
RNA isolation. J.K.-C. and F.P. provided purified human tissues. M.R. and J.F. wrote the manuscript with input from the remaining authors.

\section{References}

Ahlgren U, Pfaff SL, Jessell TM, Edlund T, Edlund H. 1997. Independent requirement for ISL1 in formation of pancreatic mesenchyme and islet cells. Nature 385: 257-260. doi:10.1038/ $385257 \mathrm{a} 0$

Ahnfelt-Rønne J, Jørgensen MC, Hald J, Madsen OD, Serup P, Hecksher-Sørensen J. 2007. An improved method for three-dimensional reconstruction of protein expression patterns in intact mouse and chicken embryos and organs. I Histochem Cytochem 55: 925-930. doi:10.1369/jhc.7A7226.2007

Atouf F, Czernichow P, Scharfmann R. 1997. Expression of neuronal traits in pancreatic $\beta$ cells: implication of neuron-restrictive silencing factor/repressor element silencing transcription factor, a neuron-restrictive silencer. I Biol Chem 272: 1929-1934. doi:10.1074/jbc.272.3.1929

Bankaitis ED, Bechard ME, Wright CV. 2015. Feedback control of growth, differentiation, and morphogenesis of pancreatic endocrine progenitors in an epithelial plexus niche. Genes Dev 29: 2203-2216. doi:10.1101/gad.267914.115

Bergemann D, Massoz L, Bourdouxhe J, Carril Pardo CA, Voz ML, Peers B, Manfroid I. 2018. Nifurpirinol: a more potent and reliable substrate compared to metronidazole for nitroreductase-mediated cell ablations. Wound Repair Regen 26: 238244. doi:10.1111/wrr.12633

Boj SF, Hwang CI, Baker LA, Chio II, Engle DD, Corbo V, Jager M, Ponz-Sarvise M, Tiriac H, Spector MS, et al. 2015. Organoid models of human and mouse ductal pancreatic cancer. Cell 160: 324-338. doi:10.1016/j.cell.2014.12.021

Bray JK, Elgamal OA, Jiang J, Wright LS, Sutaria DS, Badawi M, Borcyk MG, Liu X, Fredenburg KM, Campbell-Thompson $\mathrm{ML}$, et al. 2020. Loss of RE-1 silencing transcription factor accelerates exocrine damage from pancreatic injury. Cell Death Dis 11: 138. doi:10.1038/s41419-020-2269-7

Bruce AW, López-Contreras AJ, Flicek P, Down TA, Dhami P, Dillon SC, Koch CM, Langford CF, Dunham I, Andrews RM, et al. 2009. Functional diversity for REST (NRSF) is defined by in vivo binding affinity hierarchies at the DNA sequence level. Genome Res 19: 994-1005. doi:10.1101/gr.089086.108

Cebola I, Rodríguez-Seguí SA, Cho CH, Bessa J, Rovira M, Luengo M, Chhatriwala M, Berry A, Ponsa-Cobas J, Maestro MA, et al. 2015. TEAD and YAP regulate the enhancer network of human embryonic pancreatic progenitors. Nat Cell Biol 17: 615-626. doi:10.1038/ncb3160

Charbord J, Poydenot P, Bonnefond C, Feyeux M, Casagrande F, Brinon B, Francelle L, Aurégan G, Guillermier M, Cailleret M, et al. 2013. High throughput screening for inhibitors of REST in neural derivatives of human embryonic stem cells reveals a chemical compound that promotes expression of neuronal genes. Stem Cells 31: 1816-1828. doi:10.1002/stem .1430

Chen ZF, Paquette AJ, Anderson DJ. 1998. NRSF/REST is required in vivo for repression of multiple neuronal target genes during embryogenesis. Nat Genet 20: 136-142. doi:10.1038/ 2431

Crews ST, Pearson JC. 2009. Transcriptional autoregulation in development. Curr Biol 19: R241-R246. doi:10.1016/j.cub .2009.01.015

de Lichtenberg KH, Seymour PA, Jørgensen MC, Kim Y-H, Grapin-Botton A, Magnuson MA, Nakic N, Ferrer J, Serup P. 
2018. Notch controls multiple pancreatic cell fate regulators through direct hes1-mediated repression. bioRxiv doi:10 $.1101 / 336305$

De Vas MG, Kopp JL, Heliot C, Sander M, Cereghini S, Haumaitre C. 2015. Hnflb controls pancreas morphogenesis and the generation of $\mathrm{Ngn}^{+}$endocrine progenitors. Development 142: 871-882. doi:10.1242/dev.110759

Dobin A, Davis CA, Schlesinger F, Drenkow J, Zaleski C, Jha S, Batut P, Chaisson M, Gingeras TR. 2013. STAR: ultrafast universal RNA-seq aligner. Bioinformatics 29: 15-21. doi:10 .1093/bioinformatics/bts635

Eden E, Navon R, Steinfeld I, Lipson D, Yakhini Z. 2009. Gorilla: a tool for discovery and visualization of enriched go terms in ranked gene lists. BMC Bioinformatics 10: 48. doi:10.1186/ 1471-2105-10-48

Elhanani O, Salame TM, Sobel J, Leshkowitz D, Povodovski L, Vaknin I, Kolodkin-Gal D, Walker MD. 2020. REST inhibits direct reprogramming of pancreatic exocrine to endocrine cells by preventing PDX1-mediated activation of endocrine genes. Cell Rep 31: 107591. doi:10.1016/j.celrep.2020.107591

Gao Z, Ure K, Ding P, Nashaat M, Yuan L, Ma J, Hammer RE, Hsieh J. 2011. The master negative regulator REST/NRSF controls adult neurogenesis by restraining the neurogenic program in quiescent stem cells. I Neurosci 31: 9772-9786. doi:10.1523/JNEUROSCI.1604-11.2011

Gmyr V, Kerr-Conte J, Belaich S, Vandewalle B, Leteurtre E, Vantyghem MC, Lecomte-Houcke M, Proye C, Lefebvre J, Pattou F. 2000. Adult human cytokeratin 19-positive cells reexpress insulin promoter factor 1 in vitro: further evidence for pluripotent pancreatic stem cells in humans. Diabetes 49: 16711680. doi:10.2337/diabetes.49.10.1671

Gong S, Zheng C, Doughty ML, Losos K, Didkovsky N, Schambra UB, Nowak NJ, Joyner A, Leblanc G, Hatten ME, et al. 2003. A gene expression atlas of the central nervous system based on bacterial artificial chromosomes. Nature 425: 917-925. doi:10.1038/nature02033

Gradwohl G, Dierich A, LeMeur M, Guillemot F. 2000. Neuroge$\operatorname{nin} 3$ is required for the development of the four endocrine cell lineages of the pancreas. Proc Natl Acad Sci 97: 1607-1611. doi:10.1073/pnas.97.4.1607

Graf T, Enver T. 2009. Forcing cells to change lineages. Nature 462: 587-594. doi:10.1038/nature 08533

Gu G, Dubauskaite J, Melton DA. 2002. Direct evidence for the pancreatic lineage: NGN3+ cells are islet progenitors and are distinct from duct progenitors. Development 129: 24472457. doi:10.1242/dev.129.10.2447

Guo S, Dai C, Guo M, Taylor B, Harmon JS, Sander M, Robertson RP, Powers AC, Stein R. 2013. Inactivation of specific $\beta$ cell transcription factors in type 2 diabetes. I Clin Invest 123: 3305-3316. doi:10.1172/JCI65390

Hingorani SR, Petricoin EF, Maitra A, Rajapakse V, King C, Jacobetz MA, Ross S, Conrads TP, Veenstra TD, Hitt BA, et al. 2003. Preinvasive and invasive ductal pancreatic cancer and its early detection in the mouse. Cancer Cell 4: 437-450. doi:10.1016/S1535-6108(03)00309-X

Huch M, Koo BK. 2015. Modeling mouse and human development using organoid cultures. Development 142: 31133125. doi:10.1242/dev.118570

Huch M, Bonfanti P, Boj SF, Sato T, Loomans CJ, van de Wetering M, Sojoodi M, Li VS, Schuijers J, Gracanin A, et al. 2013. Unlimited in vitro expansion of adult bi-potent pancreas progenitors through the Lgr5/R-spondin axis. EMBO J 32: 2708-2721. doi:10.1038/emboj.2013.204
Hwang JY, Zukin RS. 2018. REST, a master transcriptional regulator in neurodegenerative disease. Curr Opin Neurobiol 48: 193-200. doi:10.1016/j.conb.2017.12.008

Jensen J, Pedersen EE, Galante P, Hald J, Heller RS, Ishibashi M, Kageyama R, Guillemot F, Serup P, Madsen OD. 2000. Control of endodermal endocrine development by Hes-1. Nat Genet 24: 36-44. doi:10.1038/71657

Johnson R, Teh CH, Kunarso G, Wong KY, Srinivasan G, Cooper ML, Volta M, Chan SS, Lipovich L, Pollard SM, et al. 2008. REST regulates distinct transcriptional networks in embryonic and neural stem cells. PLOS Biol 6: e256. doi:10.1371/jour nal.pbio.0060256

Kerr-Conte J, Pattou F, Lecomte-Houcke M, Xia Y, Boilly B, Proye C, Lefebvre J. 1996. Ductal cyst formation in collagen-embedded adult human islet preparations. A means to the reproduction of nesidioblastosis in vitro. Diabetes 45: 1108-1114. doi:10.2337/diab.45.8.1108

Kopinke D, Brailsford M, Shea JE, Leavitt R, Scaife CL, Murtaugh LC. 2011. Lineage tracing reveals the dynamic contribution of $H e s 1^{+}$cells to the developing and adult pancreas. Development 138: 431-441. doi:10.1242/dev.053843

Kopp JL, Dubois CL, Schaffer AE, Hao E, Shih HP, Seymour PA, Ma J, Sander M. 2011. Sox $9^{+}$ductal cells are multipotent progenitors throughout development but do not produce new endocrine cells in the normal or injured adult pancreas. Development 138: 653-665. doi:10.1242/dev.056499

Krentz NAJ, van Hoof D, Li Z, Watanabe A, Tang M, Nian C, German MS, Lynn FC. 2017. Phosphorylation of neurog3 links endocrine differentiation to the cell cycle in pancreatic progenitors. Dev Cell 41: 129-142.e6. doi:10.1016/j.devcel .2017.02.006

Li Z, Schulz MH, Look T, Begemann M, Zenke M, Costa IG. 2019. Identification of transcription factor binding sites using ATAC-seq. Genome Biol 20: 45. doi:10.1186/s13059-019$1642-2$

Loomans CJM, Williams Giuliani N, Balak J, Ringnalda F, van Gurp L, Huch M, Boj SF, Sato T, Kester L, de Sousa Lopes SMC, et al. 2018. Expansion of adult human pancreatic tissue yields organoids harboring progenitor cells with endocrine differentiation potential. Stem Cell Reports 10: 712-724. doi:10 $.1016 /$ j.stemcr.2018.02.005

Love MI, Huber W, Anders S. 2014. Moderated estimation of fold change and dispersion for RNA-seq data with DESeq2. Genome Biol 15: 550. doi:10.1186/s13059-014-0550-8

Luche H, Weber O, Nageswara Rao T, Blum C, Fehling HJ. 2007. Faithful activation of an extra-bright red fluorescent protein in 'knock-in' Cre-reporter mice ideally suited for lineage tracing studies. Eur I Immunol 37: 43-53. doi:10.1002/eji.200636745

Maestro MA, Boj SF, Luco RF, Pierreux CE, Cabedo J, Servitja JM, German MS, Rousseau GG, Lemaigre FP, Ferrer J. 2003. Hnf6 and Tcf2 (MODY5) are linked in a gene network operating in a precursor cell domain of the embryonic pancreas. Hum Mol Genet 12: 3307-3314. doi:10.1093/hmg/ddg355

Mamidi A, Prawiro C, Seymour PA, de Lichtenberg KH, Jackson A, Serup P, Semb H. 2018. Mechanosignalling via integrins directs fate decisions of pancreatic progenitors. Nature 564: 114-118. doi:10.1038/s41586-018-0762-2

Martin D, Allagnat F, Chaffard G, Caille D, Fukuda M, Regazzi R, Abderrahmani A, Waeber G, Meda P, Maechler P, et al. 2008. Functional significance of repressor element 1 silencing transcription factor (REST) target genes in pancreatic $\beta$ cells. Diabetologia 51: 1429-1439. doi:10.1007/s00125-008-0984-1

Martin D, Allagnat F, Gesina E, Caille D, Gjinovci A, Waeber G, Meda P, Haefliger JA. 2012. Specific silencing of the REST target genes in insulin-secreting cells uncovers their 
participation in $\beta$ cell survival. PLoS One 7: e45844. doi:10 .1371/journal.pone.0045844

Martin D, Kim YH, Sever D, Mao CA, Haefliger JA, Grapin-Botton A. 2015. REST represses a subset of the pancreatic endocrine differentiation program. Dev Biol 405: 316-327. doi:10 .1016/j.ydbio.2015.07.002

McLean CY, Bristor D, Hiller M, Clarke SL, Schaar BT, Lowe CB, Wenger AM, Bejerano G. 2010. Great improves functional interpretation of cis-regulatory regions. Nat Biotechnol 28: 495501. doi:10.1038/nbt.1630

Miguel-Escalada I, Bonas-Guarch S, Cebola I, Ponsa-Cobas J, Mendieta-Esteban J, Atla G, Javierre BM, Rolando DMY, Farabella I, Morgan CC, et al. 2019. Human pancreatic islet three-dimensional chromatin architecture provides insights into the genetics of type 2 diabetes. Nat Genet 51: 11371148. doi:10.1038/s41588-019-0457-0

Miyatsuka T, Kosaka Y, Kim H, German MS. 2011. Neurogenin3 inhibits proliferation in endocrine progenitors by inducing Cdkn1a. Proc Natl Acad Sci 108: 185-190. doi:10.1073/pnas .1004842108

Mukherjee S, Brulet R, Zhang L, Hsieh J. 2016. REST regulation of gene networks in adult neural stem cells. Nat Commun 7: 13360. doi: $10.1038 /$ ncomms 13360

Nechiporuk T, McGann J, Mullendorff K, Hsieh J, Wurst W, Floss T, Mandel G. 2016. The REST remodeling complex protects genomic integrity during embryonic neurogenesis. Elife 5: e09584. doi:10.7554/eLife.09584

Osipovich AB, Long Q, Manduchi E, Gangula R, Hipkens SB, Schneider J, Okubo T, Stoeckert CJ, Takada S, Magnuson MA. 2014. Insm1 promotes endocrine cell differentiation by modulating the expression of a network of genes that includes neurog3 and ripply3. Development 141: 2939-2949. doi:10 $.1242 /$ dev.104810

Parsons MJ, Pisharath H, Yusuff S, Moore JC, Siekmann AF, Lawson N, Leach SD. 2009. Notch-responsive cells initiate the secondary transition in larval zebrafish pancreas. Mech Dev 126: 898-912. doi:10.1016/j.mod.2009.07.002

Paul L, Walker EM, Drosos Y, Cyphert HA, Neale G, Stein R, South J, Grosveld G, Herrera PL, Sosa-Pineda B. 2016. Lack of Prox1 downregulation disrupts the expansion and maturation of postnatal murine $\beta$-cells. Diabetes 65: 687-698. doi: $10.2337 / \mathrm{db} 15-0713$

Pisharath H, Rhee JM, Swanson MA, Leach SD, Parsons MJ. 2007. Targeted ablation of $\beta$ cells in the embryonic zebrafish pancreas using E. coli nitroreductase. Mech Dev 124: 218-229. doi:10 $.1016 /$ j.mod.2006.11.005

Rezania A, Bruin JE, Arora P, Rubin A, Batushansky I, Asadi A, O'Dwyer S, Quiskamp N, Mojibian M, Albrecht T, et al. 2014. Reversal of diabetes with insulin-producing cells derived in vitro from human pluripotent stem cells. Nat Biotechnol 32: 1121-1133. doi:10.1038/nbt.3033

Rosado-Olivieri EA, Anderson K, Kenty JH, Melton DA. 2019. YAP inhibition enhances the differentiation of functional stem cell-derived insulin-producing $\beta$ cells. Nat Commun 10: 1464. doi:10.1038/s41467-019-09404-6

Rovira M, Maestro MA, Grau V, Ferrer J. 2021. Hnf1b-creER causes efficient recombination of a Rosa26-RFP reporter in duct and islet $\delta$ cells. Islets doi:10.1080/19382014.2021.1955088

Schoenherr CJ, Anderson DJ. 1995. The neuron-restrictive silencer factor (NRSF): a coordinate repressor of multiple neuron-specific genes. Science 267: 1360-1363. doi:10.1126/sci ence. 7871435
Servitja JM, Ferrer J. 2004. Transcriptional networks controlling pancreatic development and $\beta$ cell function. Diabetologia 47: 597-613. doi:10.1007/s00125-004-1368-9

Servitja JM, Pignatelli M, Maestro MA, Cardalda C, Boj SF, Lozano J, Blanco E, Lafuente A, McCarthy MI, Sumoy L, et al. 2009. Hnfla (mody3) controls tissue-specific transcriptional programs and exerts opposed effects on cell growth in pancreatic islets and liver. Mol Cell Biol 29: 2945-2959. doi:10.1128/ MCB.01389-08

Solar M, Cardalda C, Houbracken I, Martín M, Maestro MA, De Medts N, Xu X, Grau V, Heimberg H, Bouwens L, et al. 2009. Pancreatic exocrine duct cells give rise to insulin-producing $\beta$ cells during embryogenesis but not after birth. Dev Cell 17: 849-860. doi:10.1016/j.devcel.2009.11.003

Supek F, Bošnjak M, Škunca N, Šmuc T. 2011. REVIGO summarizes and visualizes long lists of gene ontology terms. PLoS One 6: e21800. doi:10.1371/journal.pone.0021800

Sussel L, Kalamaras J, Hartigan-O'Connor DJ, Meneses JJ, Pedersen RA, Rubenstein JL, German MS. 1998. Mice lacking the homeodomain transcription factor Nkx2.2 have diabetes due to arrested differentiation of pancreatic $\beta$ cells. Development 125: 2213-2221. doi:10.1242/dev.125.12.2213

Tabula Muris Consortium, Overall coordination, Logistical coordination, Organ collection and processing, Library preparation and sequencing, Computational data analysis, Cell type annotation, Writing group, et al. 2018. Single-cell transcriptomics of 20 mouse organs creates a Tabula Muris. Nature 562: 367-372. doi:10.1038/s41586-018-0590-4

Tyrberg B, Miles P, Azizian KT, Denzel MS, Nieves ML, Monosov EZ, Levine F, Ranscht B. 2011. T-cadherin (Cdh13) in association with pancreatic $\beta$-cell granules contributes to second phase insulin secretion. Islets 3: 327-337. doi:10.4161/isl.3.6 .17705

van Arensbergen J, García-Hurtado J, Moran I, Maestro MA, Xu X, Van de Casteele M, Skoudy AL, Palassini M, Heimberg H, Ferrer J. 2010. Derepression of polycomb targets during pancreatic organogenesis allows insulin-producing $\beta$-cells to adopt a neural gene activity program. Genome Res 20: 722-732. doi:10.1101/gr.101709.109

van Arensbergen J, García-Hurtado J, Maestro MA, Correa-Tapia M, Rutter GA, Vidal M, Ferrer J. 2013. Ring1b bookmarks genes in pancreatic embryonic progenitors for repression in adult $\beta$ cells. Genes Dev 27: 52-63. doi:10.1101/gad.206094 .112

Villasenor A, Chong DC, Cleaver O. 2008. Biphasic Ngn3 expression in the developing pancreas. Dev Dyn 237: 3270-3279. doi:10.1002/dvdy.21740

Wang YJ, Bailey JM, Rovira M, Leach SD. 2013. Sphere-forming assays for assessment of benign and malignant pancreatic stem cells. Methods Mol Biol 980: 281-290. doi:10.1007/ 978-1-62703-287-2_15

Whyte WA, Bilodeau S, Orlando DA, Hoke HA, Frampton GM, Foster CT, Cowley SM, Young RA. 2012. Enhancer decommissioning by LSD1 during embryonic stem cell differentiation. Nature 482: 221-225. doi:10.1038/nature10805

Yamada Y, Aoki H, Kunisada T, Hara A. 2010. REST promotes the early differentiation of mouse ESCs but is not required for their maintenance. Cell Stem Cell 6: 10-15. doi:10.1016/j .stem.2009.12.003

Zhou Q, Melton DA. 2018. Pancreas regeneration. Nature 557: 351-358. doi:10.1038/s41586-018-0088-0 


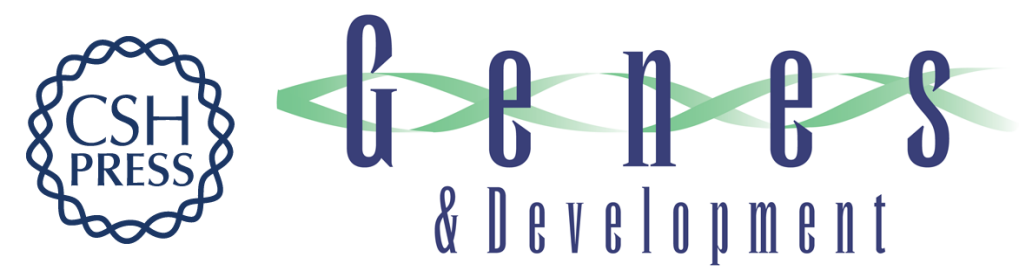

\section{REST is a major negative regulator of endocrine differentiation during pancreas organogenesis}

Meritxell Rovira, Goutham Atla, Miguel Angel Maestro, et al.

Genes Dev. 2021, 35: originally published online August 12, 2021

Access the most recent version at doi:10.1101/gad.348501.121

\section{Supplemental http://genesdev.cshlp.org/content/suppl/2021/08/11/gad.348501.121.DC1 Material}

References This article cites 70 articles, 20 of which can be accessed free at: http://genesdev.cshlp.org/content/35/17-18/1229.full.html\#ref-list-1

Creative This article, published in Genes \& Development, is available under a Creative Commons Commons License (Attribution 4.0 International), as described at License http://creativecommons.org/licenses/by/4.0/.

Email Alerting Receive free email alerts when new articles cite this article - sign up in the box at the top Service right corner of the article or click here.

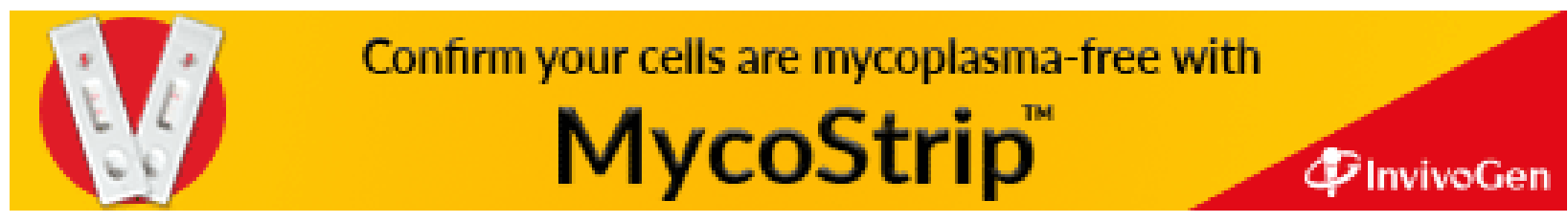

